\title{
Repair of Rat Mandibular Bone Defects by Alveolar Osteoblasts in a Novel Plasma-Derived Albumin Scaffold
}

\author{
Lorena Gallego, M.D., Ph.D.,' Luis Junquera, M.D., Ph.D., ${ }^{2,3}$ Eva García, Ph.D., ${ }^{4}$ \\ Verónica García, Ph.D., ${ }^{5}$ María Álvarez-Viejo, Ph.D.,, ${ }^{4,6}$ Serafín Costilla, M.D., Ph.D., ${ }^{3,7}$ \\ Manuel F. Fresno, M.D., Ph.D., ${ }^{3,8}$ and Álvaro Meana, M.D., Ph.D. ${ }^{4}$
}

Repair of bone deficiencies in the craniofacial skeleton remains a difficult clinical problem. The aim of this study was to evaluate a novel albumin scaffold seeded with human alveolar osteoblasts and implanted into experimental mandibular defects. An experimental solid protein scaffold was prepared with human plasmatic albumin crossed with a glutaraldehyde-type agent. Microstructure of scaffold and mechanical properties were examined using scanning electron microscopy and a stress-controlled rheometer. Bilateral critical mandibular defects were created in eight immunodeficient rats. Defects of the right side of the mandibles received the cell-scaffold construct in all animals. All left mandibular defects were left untreated as blank controls. Sections of the defects were collected at 5, 8, and 11 weeks postsurgery and processed for histological and immunohistochemical observation, computed tomography examination, and computed tomography digital analysis. Histologically, bone formation was observed in both groups at 5 weeks postsurgery, and the engineered bone became more mature after 8 and 11 weeks, which was similar to normal bone. The origin of bone-forming cells within the defects and the localization of implanted human osteoblasts were confirmed by human vimentin expression. No bone formation could be observed at any control defect. Bone density after 8 weeks was significantly higher than that of the 5-week group $(p=0.02)$, and significant differences were also observed between 8 and 11 weeks $(p<0.01)$. The results indicate the clinical feasibility of albumin scaffold loaded with human alveolar cells and that it can be used as a good alternative for bone regeneration.

\section{Introduction}

S UCCESSFUl REPAIR OF BONE DEFICIENCIES in the craniofacial skeleton, whether arising from trauma, tumor resection, or congenital disorders, continues to be a major concern to reconstructive surgeons. The use of autologous bone grafts is considered to be the golden standard for repair and reconstruction of bone. ${ }^{1,2}$ Otherwise, tissue-engineering principles applied to skeletal reconstruction may improve both morphologic and functional results while eliminating main disadvantages.

Scaffolds play an essential role in supporting bone regeneration in bone tissue engineering. Several scaffolds have been developed, including polymethylmethacrylate, porous polyethylene, hydroxyapatite, and tricalcium phosphate.
Despite their utility, as foreign bodies, these alloplastic materials may have inherent disadvantages, including increased rates of infection and extrusion. ${ }^{3}$ Otherwise, plasma-derived hydrogels are a class of biomaterials that have great scaffolding potential and have been in many tissue-engineering applications. An essential advantage is the production from the patient's own blood and used as an autologous scaffold without the potential risk of foreign body reaction or infection. The main disadvantage in craniomaxillofacial skeletal reconstruction is the low mechanical stiffness. ${ }^{4}$

Because bone is always under continuous stress, the mechanical properties of the implanted construct should ideally match those of living bone, so that an early mobilization of the injured site can be made possible. Otherwise, the scaffolds degradation rate must be tuned appropriately with the

\footnotetext{
${ }^{1}$ Department of Oral and Maxillofacial Surgery, Cabueñes Hospital, Gijón, Spain.

${ }^{2}$ Department of Oral and Maxillofacial Surgery, University Central Hospital, Oviedo, Spain.

${ }^{3}$ University of Medicine, Oviedo, Spain.

${ }^{4}$ Tissue Engineering Research Unit, Centro Comunitario de Sangre y Tejidos de Asturias, Oviedo, Spain.

${ }^{5}$ Biology and Molecular Genetics (IBGM), Valladolid, Spain.

${ }^{6}$ Transplant and Cell Therapy Unit, Central University Hospital, Oviedo, Spain.

Departments of ${ }^{7}$ Radiology and ${ }^{8}$ Pathology, Central University Hospital, Oviedo, Spain.
} 
growth rate of the neotissue, in such a way that by the time the injury site is totally regenerated, the scaffold is totally degraded. ${ }^{5}$

Physical and biological characteristics of plasma clot can be improved by crosslinking plasma albumin with glutaraldehyde to form a novel scaffold easily obtained from autologous serum. ${ }^{6}$ This method was used for development of surgical glues ${ }^{7}$ with limited mechanical strength that can be improved after a lyophilization process. ${ }^{6}$ Thus, the specific characteristics of plasmatic proteins can be used to create a new carrier with unique structural and mechanical properties. The scaffold developed in this study has a solid structure and slow degradation rate that makes it suitable for management in craniofacial surgery. This experimental scaffold with a inexpensive production could be appropriate for bone regeneration.

To pursue the possibility of repairing maxillary bone defect with tissue-engineered bone, we cultured human alveolar osteoblasts and then seeded them in this new type of scaffold. In the present study, the hypothesis tested was that cell-scaffold constructs transplanted into mandibular criticalsized defects can retain their osteogenic properties and induce new bone formation in immunocompromised rats.

\section{Materials and Methods}

\section{Scaffold fabrication}

To prepare the scaffold, $10 \mathrm{~mL}$ venous blood was obtained from the blood bank laboratories (Centro Comunitario de Sangre y Tejidos, Asturias, Spain). The blood sample was maintained $30 \mathrm{~min}$ at $37^{\circ} \mathrm{C}$ for fibrine clot retraction. Next, the blood was subjected to centrifugation for $15 \mathrm{~min}$ at $3000 \mathrm{rpm}$. The obtained serum $(5 \mathrm{~mL})$ was crosslinked with $0.5 \mathrm{~mL} 25 \%$ glutaraldehyde (Merck, Darmstadt, Germany) and was transferred to $5 \mathrm{~mL}$ disposable injection syringe. The serum/glutaraldehyde solution was maintained at room temperature for $30 \mathrm{~min}$ until solidification. Then, the solution was transferred to the freezing machine and kept at $-70^{\circ} \mathrm{C}$ overnight. After that, the syringe was cut and the frozen solution was lyophilized for $48 \mathrm{~h}$ and rehydrated in graded ethanol $(100 \%-90 \%-80 \%), 1 \mathrm{~h}$ in each one. The cylindrical sponge obtained was then cut into 5-mm-diameter, 2-mmthick sections and sterilized with $70 \%$ ethanol for $8 \mathrm{~h}$. Finally, the scaffold was neutralized in the culture medium comprising Dulbecco's modified Eagle's medium (DMEM; Biochrom, Berlin, Germany). Before cell seeding, excess fluid was removed and the sponges were placed in a 24-well culture plate, one sponge per well.

\section{Microstructure observation and mechanical test}

The microscopic structures of the novel albumin scaffold in cross and longitudinal sections were examined using a scanning electron microscope (SEM). Samples of the experimental scaffold were sputter-coated with gold, and then viewed using the SEM (JEOL JSM 6100, Tokyo, Japan). Pores were measured in a perpendicular direction through the long and minor axes.

Mechanical test was conducted using a stress-controlled rheometer (Bohlin CS-10, East Brunswick, NJ) with a CP 4/40 cone-plate geometry (plate diameter $40 \mathrm{~mm}$ ). The stress applied ranged from $10^{-1}$ to $300 \mathrm{~Pa}$. The strain and stress curves were obtained to evaluate the elastic modulus, viscous modulus, and $\sigma$ critical point.

\section{Isolation and culture of osteoblasts from alveolar bone}

Normal human bone specimens were obtained from healthy young patients who underwent oral surgery, free of bone-related disease. The cortico-cancellous bone retrieved had no soft tissue attachments and only minimal amounts of retained blood. The biopsy was washed extensively in phosphate-buffered saline (Gibco Life Technologies, Grand Island, NY), cut into pieces of approximately $2 \times 2 \mathrm{~mm}$, and seeded onto $12.5-\mathrm{cm}^{2}$ polystyrene flasks in $3 \mathrm{~mL}$ of standard culture medium consisting of DMEM (Biochrom) supplemented with $10 \%$ fetal bovine serum (FBS), $1 \% 200 \mathrm{mM}$ l-glutamine, $100 \mathrm{U} / \mathrm{mL}$ penicillin, and $100 \mu \mathrm{g} / \mathrm{mL}$ streptomycin (Gibco Life Technologies). Cells were cultured until confluence in a controlled atmosphere $\left(5 \% \mathrm{CO}_{2}, 95 \%\right.$ air, and $37^{\circ} \mathrm{C}$ ). The bone fragments were removed after 2 weeks, and cells were passaged with trypsin-ethylenediaminetetraacetic acid solution (Gibco Life Technologies) and plated in $25-\mathrm{cm}^{2}$ culture flasks.

\section{Cell seeding}

Confluent cultures of osteoblasts were trypsinized and counted using an improved Neubauer hemocytometer. The released cells were suspended in DMEM with $10 \%$ FBS. Then, DMEM was removed and cells were seeded in scaffold with osteogenic culture medium that consists of DMEM (Biochrom) supplemented with $10 \mathrm{nM}$ dexamethasone, $10 \mathrm{mM}$ $\beta$-glycerophosphate, $0.28 \mathrm{mM}$ ascorbic acid (all from Sigma, St. Louis, MO), and $10 \%$ FBS. Aliquots $(100 \mu \mathrm{L})$ of cells at a density of 5,000,000 cells $/ \mathrm{mL}$ were seeded onto albumin scaffold sponges ( $5 \mathrm{~mm}$ in diameter and $2 \mathrm{~mm}$ thick). The culture medium was changed two times per week. The cells were maintained for 1 month at $37^{\circ} \mathrm{C}$ in a fully humidified atmosphere at $5 \% \mathrm{CO}_{2}$ in air.

\section{Surgical procedure}

While performing this study we followed the rules of Declaration of Helsinki for the care and use of laboratory animals. We used eight 11- to 12-week-old nude rats (rnu/rnu, Crl: NIH-Foxn1) weighing between 250 and $270 \mathrm{~g}$. They were kept in proper environment under natural lighting and temperature, and fed water and ration ad libitum.

The animals were anesthetized with an intramuscular administration of pentobarbital sodium $(0.038 \mathrm{mg} / \mathrm{g})$ and xylazine hydrochloride $(0.075 \mathrm{mg} / \mathrm{g})$. A submandibular incision was made through the skin, subcutaneous tissue, and masseter muscle paralleling the inferior border of the mandible. The buccal and lingual surfaces of the mandible were exposed with an elevator, and two bilateral $5 \times 5-\mathrm{mm}$ fullthickness critical defects were created in the body of the mandible in each animal. ${ }^{8-10}$ Defects were created with a trephine bur in a slow-speed dental drill. To prevent overheating, $0.9 \%$ physiological saline was dropped onto the contact point between the bur and bone.

The critical-sized defects of right side of each mandible were subsequently filled with cell-scaffold constructs. The implant was trimmed to fit the defect and placed precisely into the defects, and soft tissue above the defect was closed 
with 4-0 Vicryl sutures (Ethicon, Lenneke Marelaan, Belgium). The periosteum was removed completely. To ensure that the bone defects were critical-sized, left mandibular defects were left untreated as blank controls in both groups. Two animals were sacrificed at 5, 8, and 11 weeks postoperatively, and their mandibles were harvested.

\section{Computed tomography examination}

Two animals were sacrificed and their mandibles evaluated after 5, 8, and 11 weeks, respectively. Defects of the same size on the left sides of the mandibles served as empty controls. The morphology of the implanted mandibles was assessed using computed tomography (CT; Toshiba Aquilion 16; Toshiba Medical Systems Corporation, Tochigi, Japan) with the following operating parameters: small target, $120 \mathrm{kV}, 125 \mathrm{~mA}$, 1 -s scanning time, and $0.5-\mathrm{mm}$ section thickness. Mandibles were observed in a pseudo three-dimensional display.

\section{CT images digital analysis}

CT images were analyzed by a Leica Qwin Pro image analysis system (Leica Microsystem Imaging Solutions, Cambridge, United Kingdom) to detect the areas of bone ingrowth within the defects. The implanted area was designated as the region of interest. The image analysis program then measured both the surface area of this region and the surrounding normal bone area. The Leica QWin generates data by analyzing relative pixel values of selected areas. To quantify the calcification of repaired mandibles, CT images were binarized by an automatic threshold based on the histogram frequency distribution of gray levels (0, black; 100 , white). The values represent arbitrary units and correspond directly to the radiopacity of the CT images, thus reflecting the degree of bone fill within the bone defect. All results were entered into a spreadsheet (EXCEL version 5.0; Microsoft, Madrid, Spain). Bone ingrowth was evaluated at different points postsurgery.

\section{Statistical analysis}

Data from digital analysis were analyzed by one-way analysis of variance (ANOVA) test, using SPSS 13.0 (SPSS, Chicago, IL). The differences between 5, 8, and 11 weeks were assessed with ANOVA and Bonferroni test. A $p$-value less than 0.05 was considered statistically significant.

\section{In vivo histological analysis}

Bone samples at 5, 8, and 11 weeks were infiltrated with and embedded in polymethylmethacrylate. Sectioning was performed with a rotating diamond wafering saw (Buehler, Lake Bluff, IL). The saw excursion was $900 \mu \mathrm{m}$ for each section, with approximately half of this thickness being absorbed by the blade width. The sections were then mounted on plastic slides (Wasatch Histo Consultants, Winnemucca, NV), ground to a thickness of $100 \mu \mathrm{m}$ or less, and polished. The sections were stained with hematoxylin and eosin or by von Kossa silver nitrate staining, and counterstained with safranin (Sigma), according to the manufacturer's instruction.

\section{Immunohistochemistry}

The origin of bone-forming cells within the transplants was confirmed through human vimentin expression. Small samples of implanted areas 11 weeks after surgery were fixed and stored in $4 \%$ paraformaldehyde until ready for paraffin embedding. To examine human vimentin expression immunohistochemically, endogenous peroxidase was quenched by incubating with $1 \% \mathrm{H}_{2} \mathrm{O}_{2}$ and methanol. The paraffin sections were incubated with human-specific vimentin (Novocastra, 50-fold dilution, NCL-L-VIM-V9). Color reaction was developed with hematoxylin.

\section{Results}

\section{Microstructure observation and mechanical test}

The microscopic structures of the albumin scaffold were examined using the SEM. Pore size ranged from 150 to $300 \mu \mathrm{m}$ in cross sections and 300 to $500 \mu \mathrm{m}$ in longitudinal sections. Irregular size and shape of sheet-like structure was observed, and almost all pores were interconnected (Fig. 1).

Critical sigma $(\sigma c)$ is defined by the greatest stress value before definitive deformation. This parameter was found by determining stress at the point of greatest slope in the most linear portion of the curve (viscoelastic linear region). For the experimental albumin scaffold, $\sigma c$ was $22 \mathrm{~Pa}$. We measured elastic modulus $\left(G^{\prime}\right)$ and viscous modulus $\left(G^{\prime \prime}\right)$. In all our samples $G^{\prime}$ was greater than $G^{\prime \prime}$, indicating that this scaffold present a more elastic than viscous behavior (Fig. 2).

\section{Clinical evaluation}

During the experiment, two animals died after 2 and 5 days postsurgery, respectively, of unknown causes. The six remaining animals were fed a pureed diet and exhibited a normal pattern of activity. Clinical healing was uneventful, with limited signs of inflammation. All surgical wounds remained closed without any signs of material exposure during the healing period. Five, 8 , and 11 weeks after implantation two rats were sacrificed, respectively. After dissection to the bony mandible, bone formation could be seen macroscopically in all specimens at implanted region (right). On the contrary, no bony union was observed at control region (left), and obvious soft tissue was detected in the original defect area.

\section{CT examination}

To follow-up the new bone formation and the development of bone union within the defects, CT images were taken at 5,8 , and 11 weeks postoperation. Empty control defects (left side) remained unfilled during the entire observation period. Cell-scaffold constructs had induced bone regeneration on the right side of the mandibles after 5 weeks. After 8 and 11 weeks, implanted defects appeared similar in character to adjacent native bone, and the margins of the defects could not be delineated (Fig. 3). Implants had induced bone formation at different points after surgery that was found to be grossly maintained on pseudo three-dimensional displays from week 5 to 11 .

\section{CT digital analysis}

As quantified by CT digital analysis, bone density values of the defects filled with osteoblasts-scaffold constructs were significantly greater than either unfilled bone defects (all 

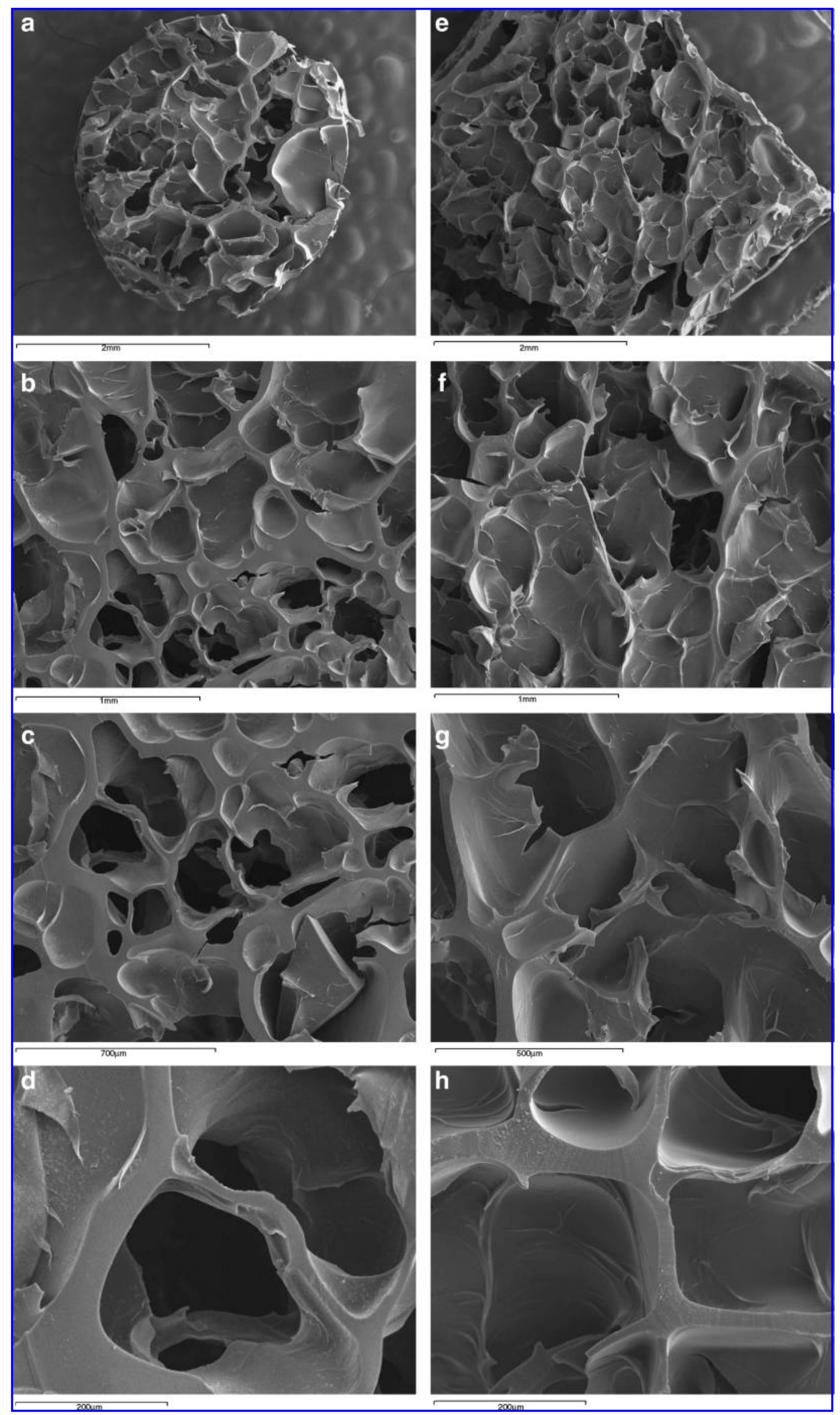

FIG. 1. Scanning electron microscopy images show microstructures of the albumin scaffold on cross sections (a-d) and longitudinal sections $(\mathbf{e}-\mathbf{h})$. The black regions represent voids, and gray or white regions represent scaffold. Original magnification: (a, e), $\times 25 ;(\mathbf{b}, \mathbf{f}), \times 50 ;(\mathbf{c}, \mathbf{g}), \times 100 ;(\mathbf{d}, \mathbf{h}), \times 200$. 


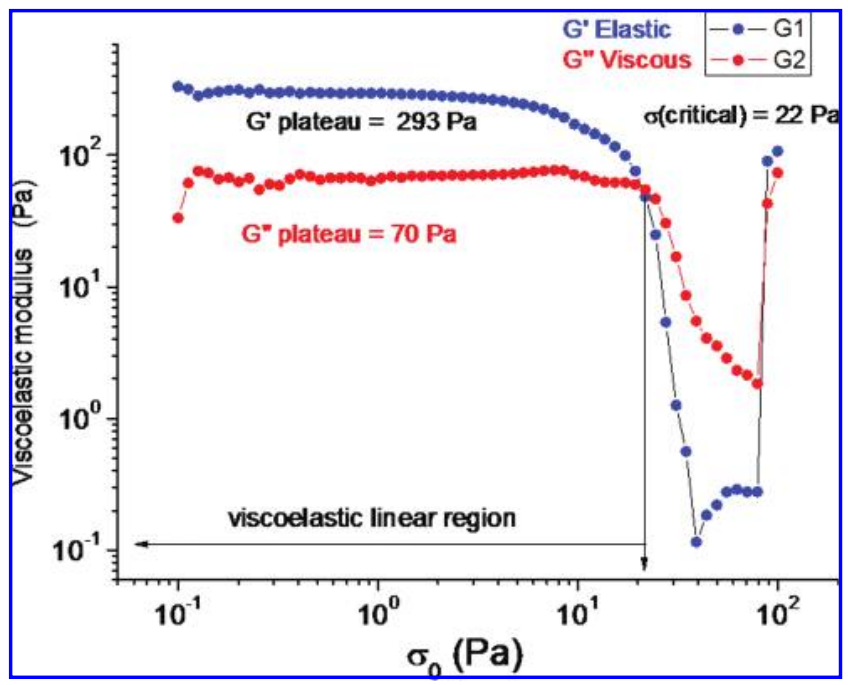

FIG. 2. Viscoelastic modulus as a function of shear stress amplitude in mechanical test for experimental albumin scaffold. Color images available online at www.liebertonline .com/ten.

control defects had values close to 0). Range values and mean of each group can be observed in Table 1 .

Samples were analyzed at three time points, 5, 8, and 11 weeks, after scaffold implantation. At 8 weeks, bone formation in implanted defects was significantly higher than that of the 5-week group ( $p=0.02$, statistically tested by ANOVA post hoc), and significant differences were also observed between 8 and 11 weeks $(p<0.01$, statistically tested by ANOVA post hoc) (Fig. 4).
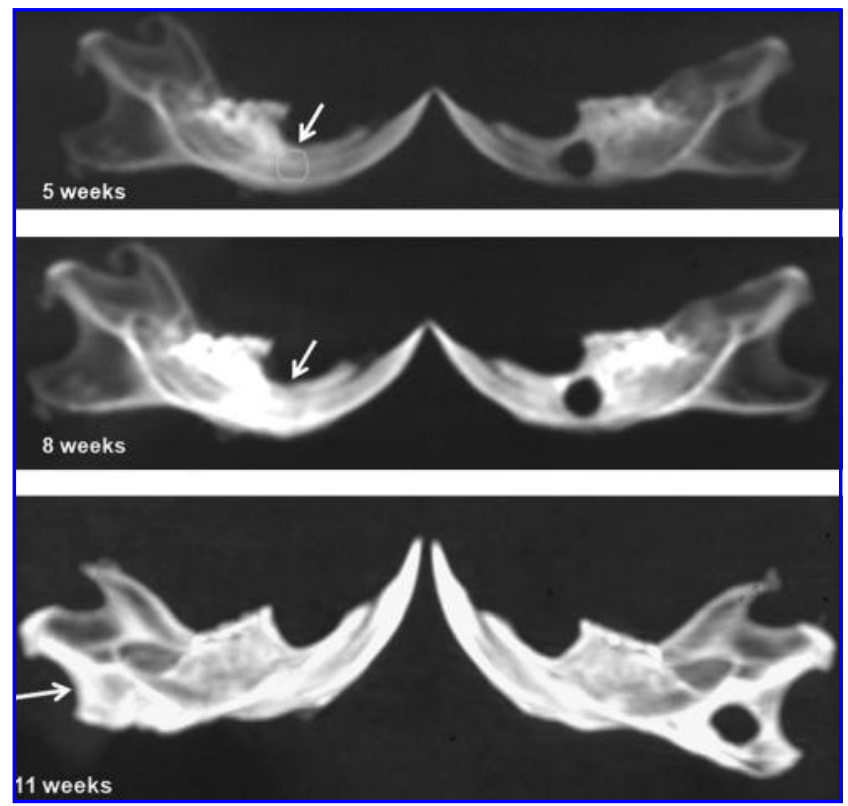

FIG. 3. Computed tomography images of treated and control defects taken at different time points post-operation. Radiolucency and minimal bone formation were observed in hemimandibles placed at the right side of each image (control). White arrows indicate area of repaired defect.
Table 1. Bone Densities of the Defects Filled with Osteoblast-Scaffold Constructs at Different

Time Points and Host Bone Based on Digital Analysis of Computed TOMOgRaphy IMAges

\begin{tabular}{cccc}
\hline & 5 weeks & 8 weeks & 11 weeks \\
\hline Implanted & 35.63 & 44.47 & 61.02 \\
defect & $(17.96-63.06)$ & $(28.49-70.35)$ & $(49.64-77.56)$ \\
Host bone & & $(50.78-79.92)$ & \\
& & &
\end{tabular}

Values shown are mean (minimum-maximum).

\section{In vivo histological analysis}

To observe the general process of alveolar bone regeneration in vivo, histological study was performed on two animals sacrificed at 5, 8, and 11 weeks, respectively. In control regions (left side) there was no evident bone regeneration even at 11 weeks postsurgery. In contrast, osteoblastcontaining transplants contained abundant new bone firmly attached to scaffold and the adjacent rat bone. The section of specimens at 5 weeks postsurgery showed new bone composed of irregular bone without a mature Haversian system (Fig. 5a). There was basophilic mineralization throughout that was proved with von Kossa staining (Fig. 5d). There was not an evident interface between the newly regenerated bone and the host bone. After 8 weeks, spaces inside the implant created by scaffold degradation were filled by ingrowth of newly formed bone (Fig. 5b, e). After 11 weeks, degradation of the scaffold was considerably advanced with simultaneous bone fill of the resulting cavities (Fig. 5c, f). Therefore, the most significant difference between early and late

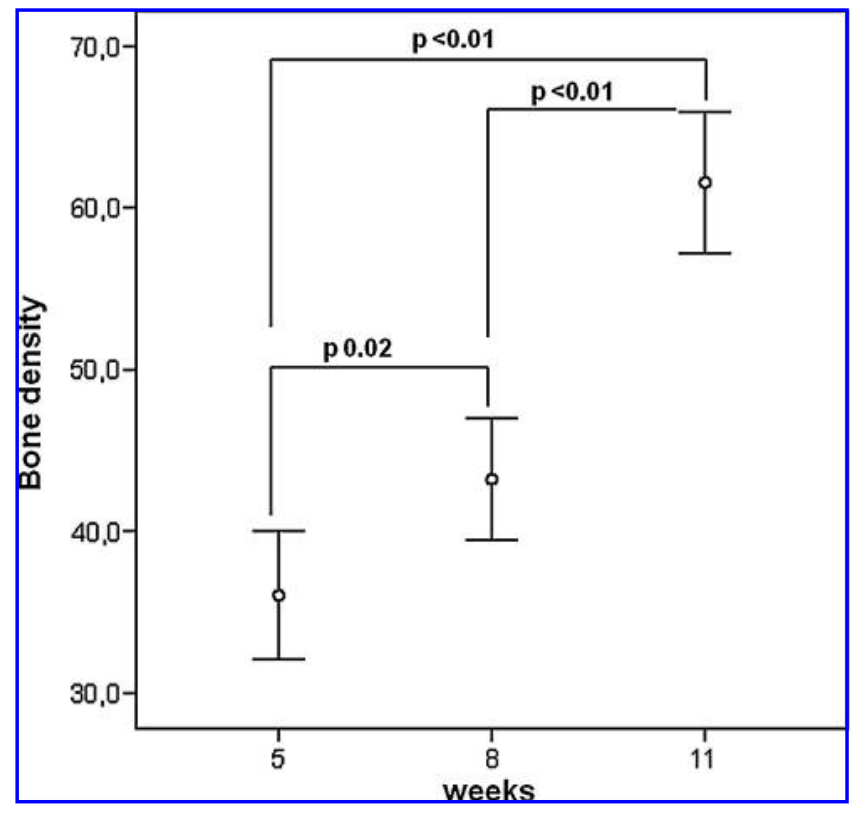

FIG. 4. Computed tomography images were analyzed using an automatic threshold based on the histogram frequency distribution of gray levels (0, black; 100, white). Samples were analyzed at 5, 8, and 11 weeks postsurgery. At 8 weeks, bone density was significantly higher than that of the 5-week group $(p=0.02)$, and significant differences were also observed between 8 and 11 weeks $(p<0.01)$. 

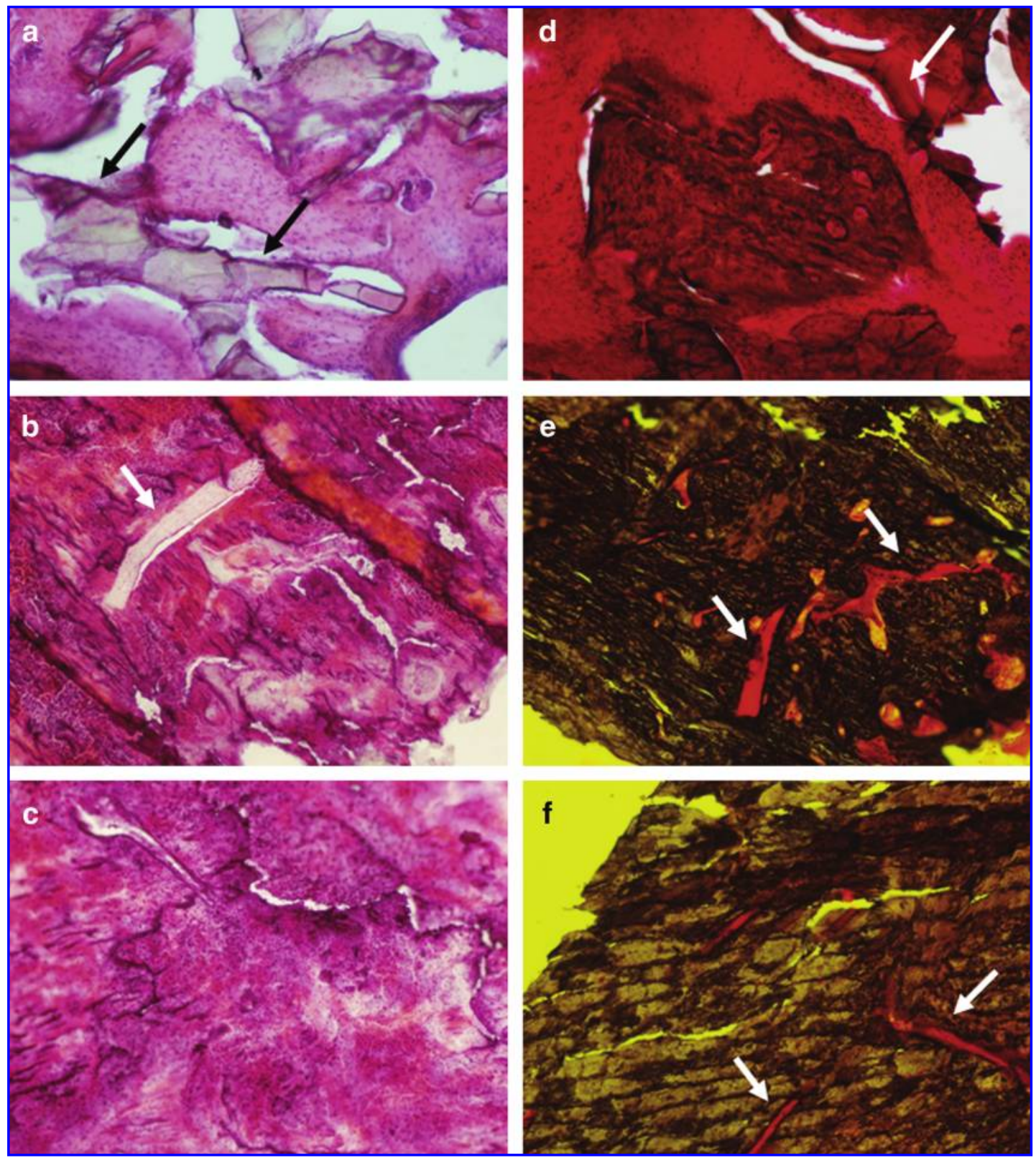

FIG. 5. Histological evaluation of tissue reaction at different time points postimplantation of osteoblasts in bone defects. (a-c) Hematoxylin-eosin stain; (d-f) von Kossa stain. (a) Five weeks after surgery, there was basophilic mineralization adjacent to scaffold. (b) Eight weeks postsurgery, the structure of newly formed bone was remolded to the structure similar to that of surrounding, and bone degradation of the scaffold was considerably advanced. (c) Eleven weeks postsurgery, the structure of new bone is almost the same as normal bone, and scaffold could not be identified in most samples. (d) Five weeks postsurgery, mineralized areas stained in brown embedded in extracellular matrix were observed near the scaffold. (e) Eight weeks after implantation, spaces inside the implant created by scaffold degradation had been filled by ingrowth of newly formed bone. (f) Eleven weeks after surgery, scaffold was almost completely degraded and replaced with mineralized tissue (black arrows and white arrows indicate scaffold; magnification, $\times 100)$. Color images available online at www.liebertonline.com/ten.

transplants was a visible reduction in the volume of residual scaffold among the late transplants and a corresponding increase in the amount of new bone, suggesting resorption of the particles and replacement with mineralized tissue.

\section{Immunohistochemistry}

The origin of bone-forming cells within the defects and the localization of implanted human osteoblasts were deter- mined by human vimentin expression. It was unknown whether transplanted human osteoblasts contributed to the bone formation, because host (rat) cells could have induced bone formation in response to protein scaffold. Anti-human vimentin served as a marker for donor cell activity because it is not present in the recipient rat cells. The positively labeled cells were nearly all located inside and around the scaffold, with stronger expression surrounding the new-formed bone. However, these cells were surrounded by negatively stained 
cells embedded among the porous of the spongy scaffold (Fig. 6).

\section{Discussion}

Although autologous bone grafts and the free flap technique still remain the standard in reconstruction of mandibular lesions, tissue engineering is a promising option to existing surgical procedures. ${ }^{11}$ In contrast to a large autogenous bone graft, tissue engineering requires only a small amount of alveolar cells to create new functional tissue. The current study demonstrates that the critical-sized defects of the rat mandible can be repaired by albumin serum-derived scaffold seeded with human-cultured osteoblasts obtained from a small cancellous bone sample. When this novel albumin scaffold construct was implanted into critical-sized defects in nude rat mandible, it was capable of differentiating to form bone matrix and of mineralizing trabeculae of bone within the defects.

Mandibular reconstruction using tissue engineering has been evaluated in a number of experimental models with a large variety of carriers and different types of cells. ${ }^{11-17}$ Biodegradable scaffold plays a pivotal role in bone engineering. The scaffold can provide a skeletal support for the growth of osteogenic cells at early stage and create enough space for new bone formation when they are degraded at later time point. ${ }^{18-20}$

The most widely used forms of serum-derived scaffolds are fibrin hydrogels, fibrin glue, and fibrin microbeads. ${ }^{4}$ Platelet-rich fibrin glue has also been used as a scaffold for bone tissue engineering. ${ }^{21}$ Newly formed bone from osteoblastic cells suspended in hydrogels has been widely demonstrated. ${ }^{22-28}$ As hydrogel-cell constructs lack adequate initial strength, usually they require additional mechanical support for the implantation of engineered bone in a weightbearing position. In most of these studies, combination of fibrin scaffold with other materials, such as hyaluronic acid, hydroxyapatite, or calcium phosphate was necessary for improving mechanical properties. ${ }^{22,24,28}$ The main goal of this study was to develop a solid human serum-derived scaffold for skeletal bone engineering. Otherwise, there is evidence that surgical glues could be potentially harmful to local tissue and generate a local inflammatory reaction. ${ }^{7}$ Moreover, toxicity of the crosslinking agent glutaraldehyde usually does not allow cell culture. Our technique using a lyophilization process after crosslinking reduces and almost eliminates toxic properties of this agent. Osteoblasts could grow and maintain their activity when seeded in this novel albumin scaffold, and no inflammatory reaction could be macroscopic or histologically observed in rats. Our results suggest that the albumin scaffold developed is an appropriate carrier for bone tissue development and can potentially be used as an autologous scaffold. Further, the easy and nonexpensive production of scaffold makes it suitable for repair bone defects.

Pore structure is very important when considering scaffolds for tissue engineering. High porosity and wellconnected pores create good mass transfer properties and increase cell viability. A porous scaffold microstructure with minimal pore size ranging from 100 to $150 \mu \mathrm{m}$ is usually required to allow tissue ingrowth. ${ }^{20}$ Pore size ranged from 150 to $500 \mu \mathrm{m}$ and showed a larger pore size on longitudinal section than on cross section of the novel albumin scaffold. The pores were highly interconnected and elongated in shape. Thus, this experimental scaffold has an appropriate architecture that allowed cellular penetration, extracellular matrix production, and neovascularization.

Different types of cells have been used for bone engineering, including adiposal stromal cells, ${ }^{29}$ periosteal cells, bone marrow stromal cells, ${ }^{12}$ induced pluripotent stem cells, ${ }^{31}$ and cells derived directly from bone. ${ }^{13}$ The relatively simple harvesting of bone marrow cells or osteoblasts from an easily accessible bone site, such as the alveolar bone of the jaw, can provide a good source of autologous bone tissue. The clinical relevance of alveolar bone as a cell source rests on the possibility of obtaining easily a small amount of biological material from a simple biopsy, without important damage to the donor site. ${ }^{32}$ Otherwise, mandibular alveolar bone is one of the most active bones in human body and may be a useful site for harvesting mature osteoblasts for bone engineering purposes in the oral cavity.

Ideal seed cells for bone tissue engineering should be able to proliferate quickly, function like osteoblasts, be nonimmunogenic when implanted in vivo, and be biocompatible

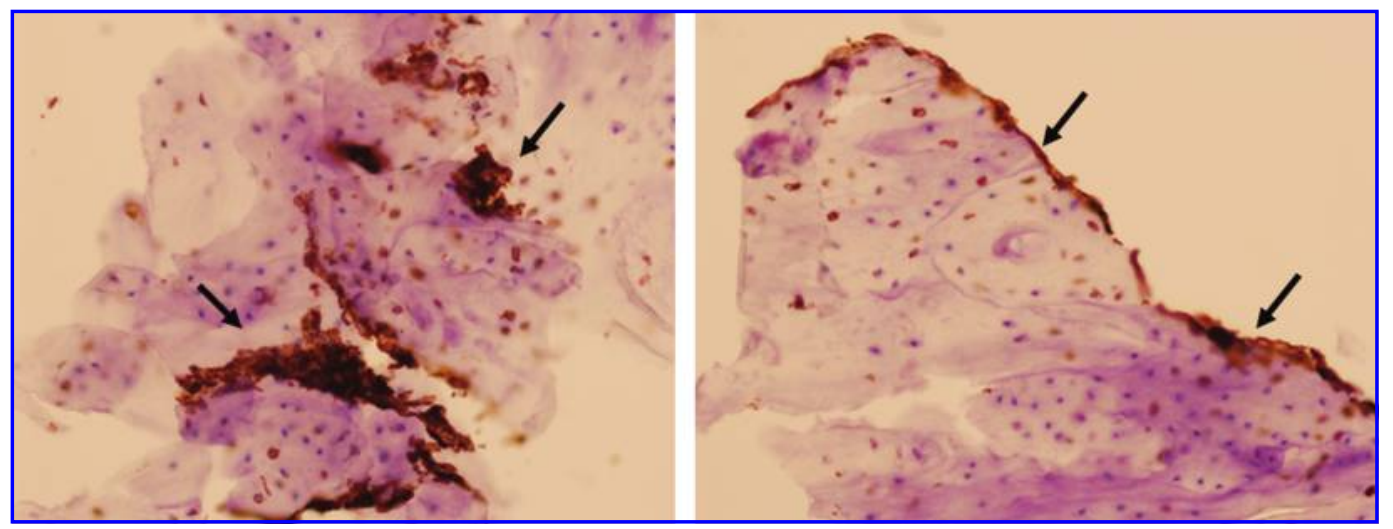

FIG. 6. Expression of human-specific vimentin in tissue sections with osteoblast implantation 11 weeks after surgery. Vimentin expression was evident inside and around the scaffold. Cells were surrounded by negatively stained cells (black arrows indicate human vimentin stained cells; magnification, $\times 200$ ). Color images available online at www.liebertonline $. \mathrm{com} / \mathrm{ten}$. 
to scaffold materials. ${ }^{1,2,33}$ Previous studies have shown that human alveolar osteoblasts can be easily expanded during in vitro culture ${ }^{34-37}$ and maintain osteogenic potential in vivo. ${ }^{11-17}$ Otherwise, alveolar bone is an easily accessible site for harvesting bone cells in the oral cavity. As the use of determined osteoblastic cells do not raise legal issues and there are no problems of immune rejection (as long as the source is autologous), determined osteoblasts can be considered one of the most important cell sources in cell-based bone reconstruction therapies at present. ${ }^{38}$ Consistent with these works, we demonstrated that human osteoblasts were capable of closing critical-sized rat mandibular defects when placed in conjunction with a new-developed scaffold. Digital image analysis and histological examination showed that after 11 weeks of implantation pore fill and total bone surface area were significantly higher than those after 8 and 5 weeks. This confirms a progressive osteoblast activity in implanted areas. New bone formation in the defect and the formation of bone islands appeared to arise from both the transplanted osteoblasts (as judged by their staining for the humanspecific vimentin) and the host cells (as judged by their negative staining for the anti-human vimentin). Cell constructs with differentiated osteoblasts and serum-derived scaffolds could not have been only involved in direct bone formation, but also appear to be osteoinductive, inducing differentiation and osteogenesis potential of host cells during the repair of the critical-sized bone defects.

The morphologic findings after 11 weeks with advanced scaffold degradation suggest that the carrier is gradually replaced by the new-formed bone. The matrix maintained its overall shape and silhouette after placement, not requiring fixation to stay in place. Particles did not migrate away from the transplant, suggesting that these particles maintain cohesion.

In this study, serum used for scaffold fabrication was obtained from the blood bank laboratories (Centro Comunitario de Sangre y Tejidos, Asturias, Spain), but future investigations will have to focus on the development of a completely autologous construct to promote the regeneration of hard tissue. In comparison with other commercial serumderived scaffolds, this carrier provides an appropriate mechanical strength for craniomaxillofacial reconstruction. An extremely easy and cheap fabrication may represent an essential advantage of this new scaffold.

In conclusion, this preliminary study demonstrates that a new human serum-derived spongy scaffold loaded with human alveolar osteoblasts can repair the critical-sized mandibular defects in nude rats. The satisfactory repair rate suggests that this might be a feasible approach for the clinical reconstruction of craniomaxillofacial bone defects. This scaffold could represent a promising tool for bone repair or augmentation in the future. However, more in vitro and in vivo investigations are still needed to prove safety and potential of this scaffold. Future work will concentrate on further evaluation of osteogenesis in this albumin scaffold implanted in segmental mandibular defects in an animal model.

\section{Acknowledgments}

This study was supported by the Fondo de Investigación Sanitaria, Instituto de Salud Carlos III (PI070174). The au- thors would like to acknowledge the technical assistance of Ana Rodríguez (Transplant and Cell Therapy Unit), Dr. Ángel Martínez Nistal (Scientific-technological Services, Oviedo University), and Dr. García López-Durán (Applied Physics Department, Granada University).

\section{Disclosure Statement}

No competing financial interests exist.

\section{References}

1. Meyer, U., Wiesmann, H.P., Berr, K., Kübler, N.R., and Handschel, J. Cell-based bone reconstruction therapiesprinciples of clinical approaches. Int J Oral Maxillofac Implants 21, 899, 2006.

2. Drosse, I., Volkmer, E., Capanna, R., De Biase, P., Mutschler, W., and Schieker, M. Tissue engineering for bone defect healing: an update on a multi-component approach. Injury 39(Suppl), S9, 2008.

3. Salgado, A.J., Coutinho, O.P., and Reis, R.L. Bone tissue engineering: state of the art and future trends. Macromol Biosci 4, 743, 2004.

4. Ahmed, T.A., Dare, E.V., and Hincke, M. Fibrin: a versatile scaffold for tissue engineering applications. Tissue Eng 14, 1, 2008.

5. Langer, R., and Vacanti, J.P. Tissue engineering. Science 260, 920, 1993.

6. Meana, A., García, E., García, V., Jorcano, J.L., del Río, M., Larcher, F., Duarte, B., and Holguin, A. Method for preparing three-dimensional structures for tissue engineering. $\mathrm{WO} / 2008 / 119855$.

7. De Somer, F., Delanghe, J., Somers, P., Debrouwere, M., and Van Nooten, G. Mechanical and chemical characteristics of an autologous glue. J Biomed Mater Res A 86, 1106, 2008.

8. Schliephake, H., Weich, H.A., Dullin, C., Gruber, R., and Frahse, S. Mandibular bone repair by implantation of rhBMP-2 in a slow release carrier of polylactic acid-an experimental study in rats. Biomaterials 29, 103, 2008.

9. Arosarena, O.A., and Collins, W.L. Bone regeneration in the rat mandible with bone morphogenetic protein-2: a comparison of two carriers. Otolaryngol Head Neck Surg 132, 592, 2005.

10. Schmitz, J.P., and Hollinger, J.O. The critical size defect as an experimental model for craniomandibulofacial nonunions. Clin Orthop Relat Res 205, 299, 1986.

11. Weng, Y., Wang, M., Liu, W., Hu, X., Chai, G., Yan, Q., Zhu, L., Cui, L., and Cao, Y. Repair of experimental alveolar bone defects by tissue-engineered bone. Tissue Eng 12, 1503, 2006.

12. Yuan, J., Cui, L., Zhang, W.J., Liu, W., and Cao, Y. Repair of canine mandibular bone defects with bone marrow stromal cells and porous beta-tricalcium phosphate. Biomaterials 28, 1005, 2007.

13. Xiao, Y., Qian, H., Young, W.G., and Bartold, P.M. Tissue engineering for bone regeneration using differentiated alveolar bone cells in collagen scaffolds. Tissue Eng 9, 1167, 2003.

14. Mankani, M.H., Kuznetsov, S.A., Wolfe, R.M., Marshall, G.W., and Robey, P.G. In vivo bone formation by human bone marrow stromal cells: reconstruction of the mouse calvarium and mandible. Stem Cells 24, 2140, 2006.

15. Abukawa, H., Shin, M., Williams, W.B., Vacanti, J.P., Kaban, L.B., and Troulis, M.J. Reconstruction of mandibular defects with autologous tissue-engineered bone. J Oral Maxillofac Surg 62, 601, 2004. 
16. Jiang, X., Gittens, S.A., Chang, Q., Zhang, X., Chen, C., and Zhang, $Z$. The use of tissue-engineered bone with human bone morphogenetic protein-4-modified bone-marrow stromal cells in repairing mandibular defects in rabbits. Int J Oral Maxillofac Surg 35, 1133, 2006.

17. Abukawa, H., Terai, H., Hannouche, D., Vacanti, J.P., Kaban, L.B., and Troulis, M.J. Reconstruction of a mandible condyle by tissue engineering. J Oral Maxillofac Surg 61, 94, 2003.

18. Hutmacher, D.W. Scaffolds in tissue engineering bone and cartilage. Biomaterials 21, 2529, 2000.

19. Wiesmann, H.P., Joos, U., and Meyer, U. Biological and biophysical principles in extracorporal bone tissue engineering. Part II. Int J Oral Maxillofac Surg 33, 523, 2004.

20. Zeltinger, J., Sherwood, J.K., Graham, D.A., Müeller, R., and Griffith, L.G. Effect of pore size and void fraction on cellular adhesion, proliferation, and matrix deposition. Tissue Eng 7, 557, 2001.

21. Zhu, S.J., Choi, B.H., Jung, J.H., Lee, S.H., Huh, J.Y., You, T.M., Lee, H.J., and Li, J. A comparative histologic analysis of tissue-engineered bone using platelet-rich plasma and platelet-enriched fibrin glue. Oral Surg Oral Med Oral Pathol Oral Radiol Endod 102, 175, 2006.

22. Wittkampf, A.R. Fibrin glue as cement for HA-granules. J Craniomaxillofac Surg 17, 179, 1989.

23. Gurevich, O., Vexler, A., Marx, G., Prigozhina, T., Levdansky, L., Slavin, S., Shimeliovich, I., and Gorodetsky, R. Fibrin microbeads for isolating and growing bone marrow derived progenitor cells capable of forming bone tissue. Tissue Eng 8, 661, 2002.

24. Weinand, C., Gupta, R., Huang, A.Y., Weinberg, E., Madisch, I., Qudsi, R.A., Neville, C.M., Pomerantseva, I., and Vacanti, J.P. Comparison of hydrogels in the in vivo formation of tissue-engineered bone using mesenchymal stem cells and beta-tricalcium phosphate. Tissue Eng 13, 757, 2007.

25. Nakamura, K., Koshino, T., and Saito, T. Osteogenic response of the rabbit femur to a hydroxyapatite thermal decomposition product-fibrin glue mixture. Biomaterials 19, 1901, 1998.

26. Fowler, E.B., Cuenin, M.F., Hokett, S.D., Peacock, M.E., McPherson, J.C., 3rd, Dirksen, T.R., Sharawy, M., and Billman, M.A. Evaluation of pluronic polyols as carriers for grafting materials: study in rat calvaria defects. I Periodontol 73, 191, 2002.

27. Le Nihouannen, D., Le Guehennec, L., Rouillon, T., Pilet, P., Bilban, M., Layrolle, P., and Daculsi, G. Microarchitecture of calcium granules and fibrin glue composites for bone tissue engineering. Biomaterials 27, 2716, 2006.

28. Umeda, H., Kanemaru, S.-I., Yamashita, M., Kishimoto, M., Tamura, Y., Nakamura, T., Omori, K., Hirano, S., and Ito, J. Bone regeneration of canine skull using bone marrow derived stromal cells and b-tricalcium phosphate. Laryngoscope 117, 997, 2007.

29. Mischen, B.T., Follmar, K.E., Moyer, K.E., Buehrer, B., Olbrich, K.C., Levin, L.S., Klitzman, B., and Erdmann, D. Metabolic and functional characterization of human adipose-derived stem cells in tissue engineering. Plast Reconstr Surg 122, 725, 2008.

30. Zhu, S.J., Choi, B.H., Huh, J.Y., Jung, J.H., Kim, B.Y., and Lee, S.H. A comparative qualitative histological analysis of tissue-engineered bone using bone marrow mesenchymal stem cells, alveolar bone cells, and periosteal cells. Oral Surg Oral Med Oral Pathol Oral Radiol Endod 101, 164, 2006.

31. Nakagawa, M., Koyanagi, M., Tanabe, K., Takahashi, K., Ichisaka, T., Aoi, T., Okita, K., Mochiduki, Y., Takizawa, N., and Yamanaka, S. Generation of induced pluripotent stem cells without Myc from mouse and human fibroblasts. Nat Biotechnol 26, 101, 2008.

32. Ferrera, D., Poggi, S., Biassoni, C., Dickson, G.R., Astigiano, S., Barbieri, O., Favre, A., Franzi, A.T., Strangio, A., Federici, A., and Manduca, P. Three-dimensional cultures of normal human osteoblasts: proliferation and differentiation potential in vitro and upon ectopic implantation in nude mice. Bone 30, 718, 2002.

33. Meyer, U., Joos, U., and Wiesmann, H.P. Biological and biophysical principles in extracorporal bone tissue engineering. Part I. Int J Oral Maxillofac Surg 33, 325, 2004.

34. Malicev, E., Marolt, D., Kregar Velikonja, N., Kreft, M.E., Drobnic, M., and Rode, M. Growth and differentiation of alveolar bone cells in tissue-engineered constructs and monolayer cultures. Biotechnol Bioeng 100, 773, 2008.

35. Yamanouchi, K., Satomura, K., Gotoh, Y., Kitaoka, E., Tobiume, S., Kume, K., and Nagayama, M. Bone formation by transplanted human osteoblasts cultured within collagen sponge with dexamethasone in vitro. J Bone Miner Res 16, 857, 2001.

36. Turhani, D., Cvikl, B., Watzinger, E., Weissenböck, M., Yerit, K., Thurnher, D., Lauer, G., and Ewers, R. In vitro growth and differentiation of osteoblast-like cells on hydroxyapatite ceramic granule calcified from red algae. J Oral Maxillofac Surg 63, 793, 2005.

37. Yefang, Z., Hutmacher, D.W., Varawan, S.L., and Meng, L.T. Comparison of human alveolar osteoblasts cultured on polymer-ceramic composite scaffolds and tissue culture plates. Int J Oral Maxillofac Surg 36, 137, 2007.

38. Handschel, J., Wiesmann, H.P., Depprich, R., Kübler, N.R., and Meyer, U. Cell-based bone reconstruction therapies-cell sources. Int J Oral Maxillofac Implants 21, 890, 2006.

Address correspondence to: Luis Junquera, M.D., Ph.D. Oviedo University Catedrático José Serrano St. Oviedo 33009 Spain

E-mail: junquera@uniovi.es

Received: July 25, 2009 Accepted: October 27, 2009 Online Publication Date: January 5, 2010 

This article has been cited by:

1. Mona K. Marei. 2010. Regenerative Dentistry. Synthesis Lectures on Tissue Engineering 2:1, 1-178. [CrossRef] 